\title{
KNOWLEDGE MANAGEMENT USING EXTERNAL KNOWLEDGE
}

\author{
AYANO FUJIWARA \\ International Public Policy, Osaka University, \\ 1-31 Machikaneyama, Toyonaka, Osaka, Japan \\ ayano3@f6.dion.ne.jp \\ TOSHIYA WATANABE \\ Policy Alternatives Research Institute, \\ The University of Tokyo, \\ 17-3-1 Hongo, Bunkyo-ku, Tokyo, Japan
}

Published 11 October 2016

\begin{abstract}
This study performed an empirical analysis of R\&D based on technologies and knowledge embodied in people hired by advanced companies as engineers in emerging countries. In recent years, emerging companies in Asia have been recruiting numerous engineers from Japanese companies for their R\&D efforts. This study empirically analysed the R\&D performance of companies for which engineers from Japanese companies have become employed. Result shows that those engineers from Japanese companies contributed to increased patent production, patent complexity, and patent quality of companies in emerging Asian countries. However, the contribution is limited. Among the engineers from Japanese companies, engineers who contribute to increased patent production and who contribute to patent complexity, and patent quality are different.
\end{abstract}

Keywords: Knowledge management; external knowledge; mobility of engineers.

\section{Introduction}

COMPANIES in emerging Asian countries have been increasingly employing engineers from companies in Japan, a technologically advanced country. The term "engineers" in this case refers to scientists, technicians, inventors, and other

This is an Open Access article published by World Scientific Publishing Company. It is distributed under the terms of the Creative Commons Attribution 4.0 (CC-BY) License. Further distribution of this work is permitted, provided the original work is properly cited. 
experts in $R \& D$. This tendency is particularly strong in the electrical machinery industry, in which Japan leads to technological development. Fujiwara (2015) analysed the movement of engineers from Japanese companies to other Asian companies by tracking manufacturers of patented inventions. Results show that 490 engineers moved from Japanese electrical machinery manufacturers to South Korean electrical machinery manufacturers, 196 engineers to Chinese companies, and 350 to companies in Asia other than Japan, South Korea, and China over the last 30 years. The study also analysed the past records of these engineers who had changed their employers, which indicated that approximately $60 \%$ had left a large Japanese company. The analysis further revealed that their patent productivity had been among Japan's highest levels and that they had been involved in patents with high technological value. The question, then, is whether those emerging companies in Asia can effectively use their engineers from Japanese companies in their R\&D strategies. To ascertain the answer, this study has analysed whether emerging Asian countries are able to make effective use of their externally acquired human resources. More specifically, an empirical analysis was performed to ascertain whether engineers from Japanese companies worked more efficiently than local engineers in $R \& D$ of those emerging Asian countries.

\section{Preceding studies}

Creating the knowledge necessary for continuous technological development solely within an organisation is extremely difficult (Song, 2003). Therefore, companies must acquire knowledge needed for their growth from external organisations such as academic and research institutions and competitors. External knowledge has played an important role also in technical learning in the industrialisation of Europe, the U.S., Japan, Korea, and Taiwan, which have recently experienced rapid growth (Freeman and Soete, 1997). External knowledge is acquired through technology transfer, reverse engineering, the use of papers published by researchers and patents applied by other companies or organisations, or through the transfer of expertise through joint research with academic or research institutions or companies or through relocation of employees, among other means.

Technologies and knowledge embodied in people, particularly are regarded as important because various types of technical information communicated through social networks are more likely to engender innovation. The following describes two reasons why a transfer of engineers is regarded as encouraging innovation. First, various knowledge and information is exchanged as human resources move from one company to another, which facilitates fusion of new knowledge in companies' R\&D efforts. Information and practices related to the most advanced science and technology are often embodied in people as non-formalised, tacit 
knowledge (Almeida and Kogut, 1999; Saxenian, 1994). Rosenkopf and Tushman (1998). These moving people having knowledge and information related to the latest science and technology are the most effective mode of transferring such knowledge and information. Several studies have been done previously on the creation of innovation through the transfer of $R \& D$ human resources such as technicians and scientists (Almeida and Kogut, 1999). Almeida and Kogut (1999) and Saxenian (1994), for instance, noted that the creation of successive world-class innovations in Silicon Valley, California, the U.S., in the 1990s had been a result of spillover of knowledge caused by frequent movement of R\&D human resources within the region. These studies analysed the intercompany movement of R\&D human resources in the Silicon Valley area and information related to patent citation using patent information and verified the frequent movement of human resources in Silicon Valley and mutual patent citation among academic institutions and companies. The other reason for a transfer of engineers to encourage innovation is an increased possibility of technological exploration as a result of engineers' movement. In general, methods of seeking knowledge are taken when technological issues arise in $R \& D$ process include the following three. One is to establish a new technology without relying on existing technologies (pioneering approach) (Ahuja and Lampert, 2001; Fleming and Sorenson, 2004). The second is to rely on technologies accumulated in the company in the past ("local search"). The last is to rely on technologies developed by others ("beyond local search") (Stuart and Podolny, 1996; Rosenkopf and Nerkar, 2001; Wajima and Watanabe, 2010). Rosenkopf and Tushman (1998) argues that corporate alliances and engineers' movement enable companies to seek technical knowledge from over a wider area than before, which facilitates innovation. Song (2003) also remarks that moving engineers help companies reach for technologically distant knowledge and increase their innovations. Many preceding studies have therefore demonstrated that engineers' movement can facilitate innovation.

The international movement of scientists and technicians in the past has largely been migration of technical brains from economically emerging countries to economically developed countries (brain drain) and among economically developed countries (brain exchange). Emerging eastern Asian countries, however, have been rapidly catching up with the economically developed world and have been growing their knowledge economies in recent years. This has caused a new movement of engineers from economically developed countries to economically emerging eastern Asian countries (Avveduto, 2012). The intention of this study, therefore, is to ascertain whether emerging eastern Asian companies have been able to have their engineers from economically developed countries achieve high R\&D efficiency. This study aims to verify the following hypothesis. 
Hypothesis: Companies in emerging eastern Asian countries are using engineers acquired from advanced companies. The R\&D performance of engineers who have moved from a company in an economically developed country to a company in an economically emerging country, therefore, is higher than that of local engineers.

\section{Method of Analysis}

\section{Propensity score matching}

The objective of this study is to analyse, which engineers who have moved from Japanese companies to eastern Asian companies and local engineers in eastern Asia contribute to innovation to a greater extent. Endogeneity often becomes a problem when performing empirical research by measuring such a performance effect. In other words, because engineers moving from Japanese companies to overseas companies are likely to be already highly skilled, a simple comparison of their contribution to innovation would not clearly indicate whether a difference in their performance derives from a difference in their potential abilities or higher contribution of engineers from Japanese companies than that of local engineers. In such a case, propensity score matching has been used more often in recent years.

Propensity score matching is an analytical method proposed by Rosenbaum and Rubin in 1983, in which similar entries within a set of observation data are extracted and compared. In the context of this study, the benefit of employing engineers from Japanese companies is to be measured by identifying local engineers whose attributes closely resemble those of engineers who have moved from Japanese companies to emerging Asian companies and comparing their performance. The analysis consists of the following three stages. The first stage is to collect data on imported engineers and local engineers and calculate a model to estimate the probability of engineers moving to overseas companies. The probability of a move to an overseas company is estimated based on a probit model using attribute data such as the number of years of service of engineers, which possibly affects their move to overseas companies, and the field of technology as explanatory variables. The second stage is to calculate the forecast, identify local engineers with propensity scores approximately equal to those of imported engineers, and match the two sides to make pairs. In other words, this operation determines those local engineers having high skills that would qualify them to be hired by foreign companies. The final stage to compare the $R \& D$ performance between the matched and paired engineers, and differences in their R\&D performance will be regarded as the effect of hiring engineers from Japanese companies. 


\section{Data}

This study analyses the effect of employing engineers from Japanese companies on the R\&D performance of emerging eastern Asian companies. This analysis is difficult without a certain number of engineers who have moved from Japanese companies. Accordingly, data on a total of five companies having numerous imported engineers, including three Korean companies, Samsung Electronics, LG Electronics, and Hyundai Motor Company, a Taiwanese company, Foxconn Technology, and a Chinese company, Huawei Technologies, were used for the analyses. There are many examples of global enterprises establishing research institutes not only in the countries in which they are headquartered, but also in other countries. This study deals with all filed patents regardless of the location of the research institute. This is because the research and development strategy of the enterprises is controlled by their headquarters, and patent application is strongly influenced by the policy of the headquarters rather than the location of their research institutes (Fujiwara, 2015).

The data are from US patents applications by these companies between January 1976 and August 2013. The reason for using a set of data that starts in 1976 is to include the increase in the number of engineers moving from Japanese companies to other Asian companies, which began around 1980. This inclusive span adjusts the error in the number of citations depending on the year of application. Because the later the patent application, the smaller the number of citations, data from the last two years were excluded from the analyses.

First, the names of all inventors of these patents to be analysed were identified. Subsequently, among the inventors employed by the five companies in the study, those from Japanese companies were labelled 1; all the others were labelled 0 . Table 1 presents the number of engineers who were incorporated in the analyses. As described later, the patent productivity of inventors, the average number of citations per patent, and the number of citations per patent were calculated to assess the R\&D performance of inventors in the eastern Asian companies. In addition, for engineers from Japanese companies, the number of years of service in Japanese companies and the area of their technical expertise (most frequent IPC

Table 1. Number of engineers included in the analysis.

\begin{tabular}{lccccc}
\hline & Samsung & Foxconn & Huawei & LG & Hyundai \\
\hline Local engineers & 37917 & 5809 & 2408 & 16645 & 3470 \\
Engineers from Japanese companies & 328 & 42 & 54 & 44 & 18 \\
Total & 38245 & 5851 & 2462 & 16689 & 3488 \\
\hline
\end{tabular}


number in the patents for which they are responsible) were identified for use in propensity score matching.

For local engineers, the number of years of service in their respective eastern Asian companies and the areas of their technical expertise were specified.

This study draws on patent data to analyse the differences in the performance of engineers who left Japanese enterprises and were subsequently employed in Chinese and Korean companies. The following issues emerge from exploring the characteristics of the employed data. First, there is the issue of determining, which key elements should be given priority when matching pairs are selected out of a large number of local engineers and transferees from Japanese enterprises. This study chooses to select matching pairs from engineers sharing similar attributes for the entire period, although other methods might deserve consideration, such as selecting matching pairs from engineers who have been employed in the same enterprise within a set time frame. This choice is justified, as problems may arise by limiting the research to persons who have been employed by the same enterprise within the exact same time frame, by nature of the fact that there would be differences in the length of employment periods of otherwise potentially matchable pairs. Second, as engineers of various nationalities are employed in global enterprises, the country of origin of engineers might be seen as an important factor, since it might affect the performance of engineers in the brainstorming process of research and development. However, it has been said that the mobility of human resources is somewhat lower in Asia compared to the EU or the US (Shapira, 1995); and that many of the engineers employed by East Asian companies are actually those who have left Japanese firms (Fujiwara, 2015). Admittedly, the dataset has its limitations, as it is extremely difficult to determine the country of origin of all inventors judging solely from patent data; for that purpose separate research would be necessary. Therefore, this study chooses instead to focus on the differences between engineers who have left Japanese companies and those who are of local origin. Third, as this study determines when the transfer of an engineer has taken place by looking at patent data, those engineers who do not appear on patents are out of the scope of the analysis. For example, engineers who have only recently been taken on, or engineers in senior positions who mainly work as advisers to their subordinates, are not considered. If the objective was to measure the performance of all engineers, then one idea would be to bring into consideration those engineers whose names do not appear in patent data. However, this study focuses on those engineers who undertake the most advanced research and development in East Asian global enterprises; as such, the rationale in excluding engineers who do not appear in patent data is to a certain extent justified. 


\section{Variables}

(1) Explained variables

This study analyses the actual effect of engineers from Japanese companies on the innovation of eastern Asian companies by comparing the level of their contribution with that of local engineers. More specifically, the comparison with local inventors was made in three respects, i.e., contribution of engineers from Japanese companies to quantitative innovation, advancement of innovation, and qualitative innovation of the eastern Asian companies.

First, the contribution to quantitative innovation represents the level of contribution of each engineer to innovation in the sense of patent production of the engineer's employer. The patent productivity of each engineer was used as the explained variable by following the examples of Pakes and Griliches (1984); Hausman et al. (1984); Hall and Jacques (1995), Crépon et al. (1997), and other studies. The patent productivity of the engineers was represented by the average number of patent applications per year in the companies calculated for each inventor. This study then aims to analyse whether a difference exists between engineers from Japanese companies and local engineers in terms of the patent productivity of the respective eastern Asian companies.

Contribution to the advancement of innovation indicates the level of complexity of technologies combined for patents to which engineers have contributed to their own companies. In this case, the number of patent citations is often used as an indicator of the complexity of technological combinations used for the invention (Watanabe, 2011). The reason is that the U.S. patent regulations might impose penalties on the violation of duty to disclose prior art, which is fulfilled by a patent applicant by submitting a list of prior art. This makes it likely that necessary prior technologies are disclosed accurately and that the number of citations helps to measure how cumulative in nature the patent is.

Finally, contribution to qualitative innovation is an indicator for measuring the quality improvement of patents to which each engineer has contributed the engineer's company. In this case, the average number of citations per patent was used. In the preceding studies, too, the number of patent citations has been used as a common indicator of patent quality (Carpenter et al., 1981; Albert et al., 1991; Harhoff et al. 1999). The number of citations refers to the number of times the patent concerned has been cited by patents applied for later. Numerous citations in other patents suggest high quality and technical assessment of the patent. Studies that have demonstrated a strong correlation between the number of citations and patent quality include Trajtenberg (1990) and Jaffe et al. (2002). Harhoff et al. (1999) verified correlation between the number of citations and patent quality using patent data from the US and Germany, based on the fact that patents with 
numerous citations tended to be renewed until expiration and that patents with only a few citations would often expire before renewal. The extent of contributions of each engineer to the production of patents with high quality and technological value can thereby be measured by calculating the number of citations per patent, to which each engineer contributed.

(2) Explanatory variables

This section aims to analyse whether engineers from Japanese companies contribute to the innovation of eastern Asian companies more than local engineers do. First, in view of the probability that each engineer moves to a foreign company, engineers who have moved from Japanese companies to eastern Asian companies were labelled 1; local engineers who have not relocated themselves were labelled 0 . Moreover, variables that presumably affect $R \& D$ performance, including the number of years of service of each inventor, technical expertise dummies (H01, $\mathrm{H} 02, \mathrm{H} 04, \mathrm{H} 05$, and other), and diversity of technical areas with experience (HHI), were established. HHI is an indicator of level of concentration, which is calculated using the sum of squares each share. The formula used for calculation is the following:

$$
\begin{aligned}
\mathrm{HHI} & =\sum_{i=1}^{n} C_{i}^{2} . \\
\mathrm{C}_{i} & : \text { Share }(\%) \text { of the } i \text { th IPC number } \\
N & =\text { International patent classification (IPC) }
\end{aligned}
$$

As for the number of years of service of each inventor, being involved in $R \& D$ activities for many years and having acquired various technical skills and knowledge are regarded as playing an important role in creating innovation (Zellner, 2003; Zucker and Michael, 1996; Braunerhjelm et al., 2010). Technical fields and diversity of technical fields were added to the variables because having experience in various technological areas or being specialised in a particular technological field is likely to be an important factor in developing new technologies.

\section{Model}

The following model was established to examine the contribution of each engineer to innovation of the eastern Asian companies.

$$
Y_{i}=\alpha+\beta X_{i}+\mathrm{MO}_{i}+\mu .
$$

In that equation, $Y$ is an index of the contribution to innovation, $X$ represents attribute data (number of years of service, area of specialised technology, and diversity of technical areas experienced) of engineers who might affect R\&D performance, and MO indicates the movement of engineers. This study has 
performed an analysis using the technique of propensity score matching to adjust the bias created by differences in attributes between the engineers from Japanese companies and local engineers. A simple comparison of their contributions to innovation (quantity, advancement, and quality) between the local engineers ("Untreated") and those from Japanese companies ("Treated") fails to isolate the difference in the potential abilities of the two groups in terms of the performance assessment. The bias is adjusted. Therefore, by matching and pairing engineers from each side having similar attributes and investigate any difference in their performance. An average treatment effect (ATE) is defined as follows: $W_{i}=1$ denotes "with treatment" and $W_{i}=0$ "without treatment".

$$
\begin{aligned}
Y_{i} & =W_{i} Y_{1 i}+\left(1-W_{i}\right) Y_{0 i}, \\
\operatorname{ATE} & =E\left(Y_{1}-Y_{0}\right) .
\end{aligned}
$$

Tests are performed to detect any difference between engineers from Japanese companies and their local counterparts after matching. If no significant difference is discovered, importing engineers from Japan and hiring local human resources will not make a difference in the company's performance. If a significant difference is identified, then hiring engineers from Japanese companies improves the company's performance. This study has adopted a matching technique called Psmatch2 of STATA.

\section{Results}

\section{Patent productivity of engineers from Japanese companies}

An analysis was performed to ascertain whether the patent productivity of engineers from Japanese companies was higher than that of their local counterparts with equivalent technical skills. Table 2 presents the results. "Unmatched" means before matching; "ATT" means after matching. A T-stat that is 1.96 or larger means that a significant difference exists. The presence of a significant difference means that the engineer from a Japanese company has higher patent productivity than that engineer's local counterpart having comparable attributes after matching. Absence of a significant difference, however, means that an engineer from a Japanese company and that engineer's local counterpart has comparable attributes after matching equivalent patent productivity. Table 3 presents a significant difference for Samsung and no significant difference from other companies, which suggests that engineers who have moved from Japanese companies to Samsung are achieving higher patent productivity than local Samsung employees. The 
Table 2. Patent productivity.

\begin{tabular}{lccccc}
\hline & Samsung & Foxcon & Huawei & LG & Hyundai \\
\hline Unmatched & & & & & \\
Treated & -1.18 & -0.62 & -0.58 & -1.53 & -1.40 \\
Controls & -1.32 & -0.90 & -0.96 & -1.35 & -1.59 \\
Difference & 0.14 & 0.28 & 0.39 & -0.18 & 0.19 \\
S.E. & 0.06 & 0.17 & 0.11 & 0.15 & 0.21 \\
T-stat & 2.37 & 1.62 & 3.43 & -1.17 & 0.9 \\
ATT & & & & & \\
Treated & -1.18 & -0.62 & -0.58 & -1.53 & -1.40 \\
Controls & -1.74 & -1.10 & -0.94 & -0.96 & -0.93 \\
Difference & 0.56 & 0.48 & 0.36 & -0.57 & -0.46 \\
S.E. & 0.15 & 0.31 & 0.21 & 0.32 & 0.44 \\
T-stat & 3.63 & 1.55 & 1.69 & -1.75 & -1.06 \\
Imported engineers & 0.06 & -0.01 & -0.02 & -0.35 & -0.45 \\
\# of years of service & $-0.10^{* * *}$ & $-0.11^{* * *}$ & $-0.19^{* * *}$ & $-0.11^{* * *}$ & $-0.12^{* * *}$ \\
Technical area & $-0.02^{* * *}$ & $-0.04^{* * *}$ & -0.01 & $0.02^{* * *}$ & -0.01 \\
Diversity of technical areas experienced & $-1.75^{* * *}$ & $-1.87^{* * *}$ & $-1.24^{* * *}$ & $-1.48^{* * *}$ & $-0.94^{* * *}$ \\
Constant term & $0.83^{* * *}$ & $1.19^{* * *}$ & $0.84^{* * *}$ & $0.58^{* * *}$ & $0.20^{* * *}$ \\
Untreated & 37,916 & 5,808 & 2,408 & 16,645 & 3,469 \\
Treated & 328 & 42 & 54 & 44 & 18 \\
Adj R-squared & 0.5103 & 0.516 & 0.5404 & 0.4492 & 0.6293 \\
\hline
\end{tabular}

Notes: ${ }^{* * *}$ : Statistically significant at the $1 \%$ level ${ }^{* *}$ : Statistically significant at the $5 \%$ level *: Statistically significant at the $10 \%$ level.

quantitative contribution of imported engineers in the other companies could not be confirmed.

(1) Applicability of complex technologies held by engineers from Japanese companies

Subsequently, an analysis was performed to ascertain whether engineers from Japanese companies produced patented technologies that were more complex than those of their local counterparts. More specifically, whether more patents to which engineers from Japanese companies contributed are based on combinations of complex technologies than the patents developed by local engineers were examined. Table 3 exhibits the results. Foxconn and LG show a significant difference although Samsung, Huawei, and Hyundai show no significant difference after matching, which suggests that those engineers who had moved from Japanese companies to Foxconn and LG contributed to the application of patents that 
Table 3. Technological complexity.

\begin{tabular}{lccccc}
\hline & Samsung & Foxcon & Huawei & LG & Hyundai \\
\hline Unmatched & & & & & \\
Treated & 1.91 & 1.94 & 2.24 & 2.19 & 1.84 \\
Controls & 1.90 & 0.10 & 2.12 & 1.96 & 1.82 \\
Difference & 0.01 & 0.10 & 0.12 & 0.23 & 0.02 \\
S.E. & 0.04 & 0.10 & 0.08 & 0.12 & 0.20 \\
T-stat & 0.23 & 0.98 & 1.47 & 1.94 & 0.08 \\
ATT & & & & & \\
Treated & 1.91 & 1.94 & 2.24 & 2.19 & 1.84 \\
Controls & 1.69 & 1.40 & 1.88 & 1.73 & 1.91 \\
Difference & 0.22 & 0.54 & 0.36 & 0.46 & -0.07 \\
S.E. & 0.12 & 0.22 & 0.22 & 0.21 & 0.33 \\
T-stat & 1.89 & 2.47 & 1.63 & 2.18 & -0.22 \\
Imported engineers & 0.01 & 0.09 & 0.11 & 0.01 & 0.21 \\
\# of years of service & $-0.01^{* * *}$ & $-0.01^{* * *}$ & $-0.01^{* * *}$ & $-0.01^{* * *}$ & $0.01^{*}$ \\
Technical area & $0.01^{* * *}$ & $0.02^{* * *}$ & 0.05 & $0.01^{* * *}$ & 0.07 \\
Diversity of technical areas experienced & $-0.30^{* * *}$ & $-0.26^{* * *}$ & $-0.33^{* * *}$ & $-0.30^{* * *}$ & $0.00^{* * *}$ \\
Constant term & $2.18^{* * *}$ & $2.02^{* * *}$ & $2.21^{* * *}$ & $2.18^{* * *}$ & $1.45^{* * *}$ \\
Untreated & 37,702 & 5,797 & 2,400 & 16,457 & 3,420 \\
Treated & 324 & 42 & 54 & 44 & 15 \\
Adj R-squared & 0.0278 & 0.0317 & 0.0418 & 0.0385 & 0.0131 \\
Pan & & & & & \\
\hline
\end{tabular}

Notes: ${ }^{* * *}$ : Statistically significant at the $1 \%$ level $^{* *}$ : Statistically significant at the $5 \%$ level *: Statistically significant at the $10 \%$ level.

combined complex technologies to a greater degree than their local counterparts having comparable attributes.

(2) Quality of patents of engineers from Japanese companies

Furthermore, whether the quality of patents to which engineers from Japanese companies contributed in eastern Asian companies was higher than the quality of patents contributed to by local engineers was examined. Table 4 presents the results of the analysis. Although a significant difference was found for LG, the other companies indicate no significant difference after matching, which suggests that those R\&D human resources who had moved to LG produced patents of higher quality than the local engineers of LG with equivalent attributes did.

(3) Discussion

This study analysed the R\&D performance of engineers who had moved from Japanese companies to emerging Asian countries in terms of the three aspects of patent productivity, technological complexity, and improvement of patent quality. The analytical results supported the hypothesis in the case of some of the companies in the 
Table 4. Patent quality.

\begin{tabular}{|c|c|c|c|c|c|}
\hline & Samsung & Foxcon & Huawei & LG & Hyundai \\
\hline \multicolumn{6}{|l|}{ Unmatched } \\
\hline Treated & 1.07 & 0.82 & 0.31 & 1.42 & 1.06 \\
\hline Controls & 1.34 & 1.03 & 0.68 & 1.26 & 1.05 \\
\hline Difference & -0.27 & -0.21 & -0.37 & 0.17 & 0.02 \\
\hline S.E. & 0.07 & 0.22 & 0.16 & 0.20 & 0.35 \\
\hline T-stat & -3.69 & -0.97 & -2.28 & 0.81 & 0.05 \\
\hline \multicolumn{6}{|l|}{ ATT } \\
\hline Treated & 1.07 & 0.82 & 0.31 & 1.42 & 1.06 \\
\hline Controls & 0.99 & 0.48 & 0.54 & 0.51 & 0.59 \\
\hline Difference & 0.08 & 0.34 & -0.23 & 0.91 & 0.47 \\
\hline S.E. & 0.22 & 0.46 & 0.29 & 0.40 & 0.80 \\
\hline T-stat & 0.37 & 0.75 & -0.81 & 2.28 & 0.58 \\
\hline Imported engineers & -0.16 & 0.27 & 0.03 & $0.53^{* * *}$ & $0.99^{* * *}$ \\
\hline \# of years ofservice & $0.11^{* * *}$ & $0.17^{* * *}$ & $0.16^{* * *}$ & $0.11^{* * *}$ & $0.13^{* * * *}$ \\
\hline Technical area & $-0.02^{* * *}$ & $-0.06^{* * *}$ & 0.00 & $0.01^{* *}$ & 0.00 \\
\hline $\begin{array}{l}\text { Diversity of } \\
\text { technical areas } \\
\text { experienced }\end{array}$ & $0.23^{* * *}$ & $0.58^{* * *}$ & $0.43^{* * *}$ & $0.32^{* * *}$ & $0.50^{* * *}$ \\
\hline Constant term & $0.15^{* * *}$ & $-0.53^{* * *}$ & $-0.54^{* * *}$ & $-0.12^{* * *}$ & $-0.69^{* * *}$ \\
\hline Untreated & 31,064 & 4,219 & 1,540 & 13,330 & 2,302 \\
\hline Treated & 257 & 32 & 35 & 31 & 12 \\
\hline Adj R-squared & 0.2163 & 0.4054 & 0.191 & 0.2156 & 0.3572 \\
\hline
\end{tabular}

Notes: ${ }^{* * *}$ : Statistically significant at the $1 \%$ level ${ }^{* *}$ : Statistically significant at the $5 \%$ level *: Statistically significant at the $10 \%$ level.

study, in which the engineers from Japanese companies outperformed their local counterparts in terms of $\mathrm{R} \& \mathrm{D}$. The results also revealed, however, that higher patent productivity and higher technological complexity or patent quality could not be achieved concurrently. A possible cause of this is that each company expects its imported engineers to increase either its patent production efficiency or R\&D quality.

On the other hand, the differences in performance of "imported" and local engineers have been shown to be non-significant. This implies that they have not been able to take advantage of the "imported" engineers effectively. Chinese and Korean enterprises have grown rapidly in recent years, and their technological expertise has also advanced apace (Fujiwara, 2015). The lack of significant differences in the performance of "imported" and local engineers seems to arise from the fact that when engineers with similar careers and in similar specialised fields are employed, engineers from technologically advanced companies are not effectively utilised. 


\section{Conclusion}

This study has examined the contributions of engineers from Japanese companies to innovation in Asia. The results indicate that engineers who have changed their employment to work with Samsung have achieved high patent productivity, those who moved to Foxconn excel in application of complex technologies for innovation, and those who moved to LG demonstrate high applicability of complex technologies and patent quality. Whereas such outperformance of engineers from Japanese companies over engineers in emerging eastern Asian companies in R\&D was verified only in some of the companies in the study, the high R\&D performance particularly of engineers who have moved to the three mature companies, including Samsung, Foxconn, and LG, are noteworthy. This result suggests that these companies are making effective use of their engineers from Japanese companies to achieve superior performance. A previous study has conducted research on the preferred types of engineers whom the Chinese and Korean enterprises have tended to employ from Japan in the past two decades. As a result, Samsung and LG were found to choose Japanese engineers capable of an advanced degree of technological complexity, whereas Huawei tended to select engineers who have a track record of filing patents of high quality. It appears that the differences in the types of engineers employed may have resulted in the differences stated above. On the other hand, no significant difference was found for Huawei or Hyundai, which might be said to be in their growth stage. These companies might not be using their human resources as efficiently. A previous study has shown that when employing engineers overseas, Chinese enterprises actively employ young engineers, whereas Korean companies prefer engineers who have had long careers (Fujiwara, 2015). It seems that each company scouts engineers from foreign companies in a manner in keeping with its own research and development strategy; however, if the technological capabilities of the hosting company are low, they are not able to make effective use of the "imported" engineers.

The findings in this study imply that the result of employing skilled R\&D human resources from outside the company varies depending on the company in terms of increased quantity, technological advancement, and quality. A conceivable explanation for such differences in the effect of hiring external human resources is the differences in the $R \& D$ human resource management and the purpose of importing such human resources. In general, companies in emerging countries often employ human resources from companies in developed countries for salaries higher than their local employees. If the imported human resources are not achieving high performance, then the management should pursue further improvements. 
This research has dealt with the degree to which Korean, Chinese, and Taiwanese companies can effectively utilise the engineers they recruit from Japanese enterprises, and has revealed that one Taiwanese and two Korean companies have taken advantage of "imported" engineers in further research and development performance, both qualitatively and quantitatively. It is often said that communication between Korea, China, and Japan is challenging because of the language differences; however, the results of this study seem to reveal that whether or not the "imported" engineers are effectively utilised depends on the technological levels of each company, rather than the nationalities of the engineers. Thus, companies with already advanced technological capabilities, an established corporate history, and a large amount of sales, like Samsung, LG, and Foxcon, can effectively utilise engineers recruited from technologically advanced companies. The findings of this study imply that the advantages of imported engineers cannot be utilised unless the hosting company has already achieved certain capabilities in technology.

This study has left some issues to be addressed in future investigations. First, the analysis used data of engineers who had moved from Japanese companies to five companies in China, South Korea, and Taiwan. The range of countries and companies in the analysis must be increased. Second, whereas the results of this study identified those companies making effective use of their imported knowledge and those companies that did not, determining the cause of this result will necessitate a separate investigation.

\section{References}

Ahuja, G and CM Lampert (2001). Entrepreneurship in the large corporation: A longitudinal study of how established firms create breakthrough inventions. Strategic Management Journal, 22, 521-543.

Albert, MB, D Avery, F Narin and P McAllister (1991). Direct validation of citation counts as indicators of industrially important patents. Research Policy, 20, 251-259.

Almeida, P and B Kogut (1999). Localization of knowledge and the mobility of engineers in regional networks. Management Science, 45(7), 905-917.

Avveduto, S (2012). High skilled migration: still a brain drain problem?Rivista Italiana di Economia Demografia e Statistica, 66(2), 39-56.

Braunerhjelm, P, JA Zoltan, BA David and C Bo (2010). The missing link: Knowledge diffusion and entrepreneurship in endogenous growth. Small Business Economics, 34(2), 105-125.

Carpenter, M, N Francis and W Patricia (1981). Citation rates to technologically important patents. World Patent Information, 3, 160-163. 
Crépon, B, E Duguet and J Mairesse (1997). Research, innovation and productivity: An econometric analysis at the firm level. Economics of Innovation and New Technology 7(2), 115-158.

Fleming, L and O Sorenson (2004). Science as a map in technological search. Strategic Management Journal, 25(8-9), 909-928.

Freeman, C and L Soete (1997). The Economics of Industrial Innovation. East Sassex: Psychology Press.

Fujiwara, A (2015). Empirical analysis of the effect of learning by hiring by follower firm. The thesis for a doctorate, Department of Technology Management for Innovation, Graduate School of Engineering The University of Tokyo.

Hall, B and M Jacques (1995). Exploring the relationship between R\&D and productivity in French manufacturing firms. Journal of Econometrics, 65(1), 263-293.

Harhoff, D, N Francis, FM Scherer and V Katrin (1999). Citation frequency and the value of patented inventions. The Review of Economics and Statistics, 81(3), 511-515.

Hausman, J, B Hall and Z Griliches (1984). Econometric models for count data with an application to the patents R\&D relationship. Econometrica, 52, 909-938.

Jaffe, A, M Trajtenberg and M Fogarty (2002). The meaning of patent citations: Reports on the NBER/Case-western reserve survey of patentee. In Patents, Citations and Innovations, A Jaffee and M Trajtenberg, (Eds.) The MIT Press.

Pakes, A and Z Griliches (1984). Estimating distributed lags in short panels with an application to the specification of depreciation patterns and capital stock constructs. Review of Economic Studies, 51(2), 243-262.

Rosenkopf, L and A Nerkar (2001). Beyond local search: Boundary — spanning, exploration, and impact in the optical disk industry. Strategic Management Journal, 22, 287-306.

Rosenkopf, L and ML Tushman (1998). The coevolution of community networks and technology: Lessons from the flight simulation industry. Industrial and Corporate Change, 7, 311-346.

Shapira, P (1995). The R\&D Workers: Managing Innovation in Britain, Germany, Japan, and the United States. Santa Barbara, California: Greenwood Publishing Group.

Saxenian, A (1994). Regional Advantage. Cambridge, Massachusetts: Harvard University Press.

Song, J, P Almeida and G Wu (2003). Learning-by-hiring: When is mobility more likely to facilitate interfirm knowledge transfer? Management Science, 49(4), 351-365.

Stuart, TE and JM Podolny (1996). Local search and the evolution of technological capabilities. Strategic Management Journal, 17, 21-38.

Trajtenberg, M (1990). A penny for your quotes: Patent citations and the value of innovations. The Rand Journal of Economics, 21(1), 172-187.

Wajima, K and T Watanabe (2010). Local search and Beyond local search. The thesis for a master, Department of Technology Management for Innovation, Graduate School of Engineering, The University of Tokyo.

Watanabe, T (2011). The patent information to help corporate management, Japio year book 2011, 68-73. 


\section{A. Fujiwara \& T. Watanabe}

Zellner, C (2003). The economic effects of basic research: Evidence for embodied knowledge transfer via Scientists' migration. Research Policy, 32, 1881-1895.

Zucker, LG and RD Michael (1996). Star scientists and institutional transformation: Patterns of invention and innovation in the formation of the biotechnology industry. Proceedings of the National Academy of Sciences of the United States of America, 93(23), 12709-12716. 